\author{
Military Technical College \\ Kobry El-Kobba, \\ Cairo, Egypt
}

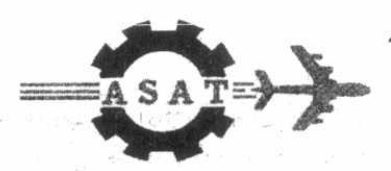

11-th International Conference

Aviation Technology

\title{
THERMAL DEFORMATION ANALYSIS OF MICROSATELLITE STRUCTURE
}

\author{
Gasser F. Abdelal ${ }^{1}$, Ayman Atef ${ }^{2}$
}

\begin{abstract}
Mounting accuracy of satellite payload and ADCS (attitude determination and control subsystem) seats is one of the requirements to achieve the satellite mission with acceptable performance. Components of mounting inaccuracy are technological inaccuracies, residual plastic deformations after loading (during transportation and orbital insertion), elastic deformations, and thermal deformations during orbital operation. This paper focuses on estimation of thermal deformations of satellite structure. Thermal analysis is executed by applying finite-difference method (IDEAS) and temperature profile for satellite components case is evaluated. Then, Perform thermal finite-element analysis applying the finitedifference model results as boundary conditions; and calculate the resultant thermal strain. Next, applying the resultant thermal strain, perform finite-element structure analysis to evaluate structure deformations at the payload and ADCS equipments seats.
\end{abstract}

\section{Keywords}

Aerospace, Satellite, Structure, thermal deformation, finite difference, Finite element, and mounting accuracy.

\footnotetext{
${ }^{1}$ Gasser F. Abdelal, Ph.D., Deputy Group Leader - Satellite Structure (EGYPTSAT-1), National Authority for Remote Sensing and Space Science (NARSS).

${ }^{2}$ Ayman Atef, Senior Structure Engineer - Satellite Structure (EGYPTSAT-1), National Authority for Remote Sensing and Space Science (NARSS).
} 


\section{Introduction}

The predicting of thermally induced structural responses of high precision spacecraft components operating in space environment is a complex and interdisciplinary problem. The thermal-structural response analysis of a spacecraft component operating under space orbital environment involves the following analysis work: 1) orbital heating loads analysis; 2) thermal modeling and the calculating of temperature profile; 3 ) structural modeling and the calculating of thermally-induced structural response. The temperature profiles of the satellite components were obtained by using I-DEAS TMG thermal analysis software based on finite difference technique, while the structural response was calculated using ANSYS structural analysis software based on finite element method.

Some general aspects of the thermal design and a detailed analysis of the battery and its compartment of China/Brazil Earth Resources Satellite is presented by Muroaka et al. [4]. The battery compartment is analyzed, using mathematical modeling, to calculate the radiator area and heater power consumption. The battery internal temperature gradients are estimated, also using mathematical modeling, to verify the cells package design. The thermal package developed was used to create the thermal model where the temperature distributions are predicted by a thermal analyzer based on finite differences.

Furthermore, Moffitt addresses thermal modeling used during the design and analysis of the Combat Sentinel Satellite (CSSAT) [5]. An overview of the analysis used to make design decisions and create working thermal models is discussed. A thermal model of the satellite developed using I-DEAS TMG is also explained. Results from the thermal vacuum chamber tests are presented and compared to the analysis. Finally, the correlated thermal model is used to predict temperatures during extreme orbital heating environments.

The satellite under study is a remote-sensing satellite and instruments provide lowcost, multipurpose, land remote-sensing data for Earth. It carries payloads onboard called the Multi-band Earth Imager (MBEI).

\section{THERMAL MODEL}

This section describes the orbital thermal analysis of the satellite developed and implemented in I-DEAS TMG software. The model includes on-orbit heating loads analysis, view factor calculating, thermal analysis to obtain the temperature distributions. The following will represent the satellite thermal model and all the used parameters of the thermal model will be listed and the analysis will be discussed.

The design of the thermal control system of this satellite can be done in two ways, passive and active. The conceptual thermal design of this satellite will base on the 
low mass requirement of this satellite. Due to this limitation, the satellite will not have an active thermal subsystem since active subsystem requires a large amount of mass together with power which is both extremely limited in this mission. The satellite orbits Earth at an altitude of $668 \mathrm{~km}$ in a Sun-synchronous polar orbit with an inclination of $98^{\circ}$. Table 1 lists some general information about the satellite.

\subsection{GMM Construction}

The thermal analysis involves constructing a geometric math model (GMM) and a thermal math model (TMM) of the satellite and identifying analysis cases to be run. The GMM and the TMM serve different purposes. The GMM is a mathematical representation of the physical surfaces, of the satellite and is used to calculate black body radiation couplings between surfaces as well as heating rates due to environmental fluxes. The TMM is most often a lumped parameter network representation of the thermal mass and conduction and radiation couplings of the satellite, and is used to predict satellite temperatures. The radiation interchange couplings and environmental heat fluxes calculated by the GMM are used in constructing the TMM. Both the GMM and TMM are constructed and executed using I-DEAS TMG.

Figure 1 shows the deployed configuration of the studied satellite. The satellite is shaped as a rectangular structure with the dimensions of $640 \times 640 \times 680 \mathrm{~mm}$. The main carrying structure consists of modules and two lower and upper mounting plates.

The satellite structure is the frame that all the other on-board subsystems are attached to. Heat shields are installed on satellite structure to protect the internal subsystems from the space environment which includes sunlight and other radiations. The structural design consists of aluminum modules each $300 \times 380 \mathrm{~mm}$ with different heights and containing a different subsystem. The assembled body of the satellite has the modules stacked in a cubic block with the lower and upper plates by studs. The module on the bottom holds the computer. In the next module will be the transmitter electronics and above it the attitude control. The middle module will hold the power regulating module and then battery in the top. The solar arrays are fixed to the outside of this aluminium box by means of rotation mechanisms, which deploy after the separation of the satellite from the launch vehicle.

The satellite is oriented in the orbital coordinate system by the longitudinal axis pointed to Earth, and diagonal plane connecting lateral edges in plane I-III lies in the flight plane as shown in Fig. 2.

First, the GMM of the satellite was constructed using I-DEAS TMG. The model consists of a simple representation of the satellite and the payload. It was constructed using rectangular, circular, and cylindrical surface elements, and each 
surface was assigned the appropriate solar absorptivity and emissive. Dimensions and mass of each component of the satellite have can be found in Table 2.

In order to simulate the physical properties of each component, several materials have been created. However, because of the very severe thermal environment, those materials should either have a very low thermal expansion to avoid any compression or expansion in the satellite structure or a very high conductivity in order to ensure a homogeneous temperature distribution. Table 3 lists the different materials and their associated properties.

The next step is to determine the thermo-optical surface properties. Because that the satellite is not very energetic, all the exterior surfaces -heat shields, upper, and lower mounting plates- are selected to be black coated. On the interior of the satellite, it is not desired to exchange energy with the exterior surfaces, thus white paint is used. The emissive value used for solar cells was an effective value found by taking the emissive of the solar cell material and subtracting the cell efficiency. Table 4 gives the values of different thermo-optical properties of different coatings.

The next step was to mesh the model. All the satellite components were modeled as a thin shell mesh. For this to be implemented, the model has to be divided into a network of elements.

The element chosen from the I-DEAS TMG library was linear quadrilateral thin. This type of elements assumes a constant thickness. Because of the small thickness of all the elements, this thin shell was the most appropriate element which could represent it without using an excessive number of elements.

Many different elements were created on all surfaces. Each one has a different thickness. When the volume was meshed, shell elements were used with a thickness chosen to result in approximately the same mass as the structure. The basic block unit is shown in Fig. 3 after meshing.

The control volume's computational domain consisted of 7098 elements with 9216 nodes. The rotation mechanisms were excluded from the geometrical and finite element meshing for simplification. Thermal couplings were created between the solar arrays and the upper mounting plate -in the TMM- in order to simulate the conductive links between them. The satellite after complete meshing is presented in Fig. 4.

\subsection{TMM Construction}

The TMM consists of elements representing parts of the satellite, conduction and radiation exchange between those elements, and boundary conditions such as environmental heating and internal heat generation rates. 
The satellite will experience various temperatures as it is orbiting the earth because of various reasons such as solar radiation, albedo radiation, Earth radiation, internal power consumption, and the cold surrounding environment $\left(2.7^{\circ} \mathrm{K}\right)$.

For the satellite ability to fly in a specified orbit, the entire range of $\beta$ angles must be studied. Calculations were then made at altitudes of $668 \mathrm{~km}$ to bracket expected $\beta$ angles. The $\beta$ angle is defined mathematically as [1]:

$$
\beta=\sin ^{-1}\left(\cos \delta_{\mathrm{S}} \cdot \operatorname{sini} \cdot \sin \left(\Omega-\Omega_{\mathrm{S}}\right)+\sin \delta_{\mathrm{S}} \cdot \operatorname{cosi}\right)
$$

where

$\beta=$ beta angle

$\delta_{\mathrm{s}}=$ declination of the sun

$\mathrm{i}=$ orbit inclination

$\Omega=$ right ascension of the ascending node

$\Omega_{\mathrm{S}}=$ right ascension of the sun

To achieve sun synchronous orbit, the local time of descending node $\left(\Omega-\Omega_{\mathrm{S}}\right)$ and the orbit inclination (i) should be constant. It should be noted that, due to change in the sun's declination over the year, $23.45^{\circ}$ to $-23.45^{\circ}$, the $\beta$ angle is not constant but varies over a small range. The $\beta$ angle history during one year is shown in Fig. 5 .

Based on the satellite operating modes and thermal design requirements, one significant thermal design analysis case was identified as shown in Table 5. At $\beta=23.7$, which occurs during winter solstice, the satellite spends more time in the sun, thereby increasing the orbit average solar load and it will be considered as the hot operating case conditions. This case includes maximum solar heating, maximum Earth IR and albedo radiations, and maximum (end of life) solar absorptivity on the external surfaces.

The GMM was then run using I-DEAS TMG to calculate the radiation interchange factors between all surfaces. The GMM was then placed mathematically into the proper orbit and attitude. Solar, Earth IR, and albedo heat loads absorbed on each surface were calculated for 50 points (7.2-degree intervals) around the orbit. The results have been computed on 30 orbits (about 2 days) in order to check the stability of the solution. Sample orbit plot is shown in Fig. 6.

The satellite has a average operational loads of approximately $65 \mathrm{~W}$. For the design orbit, orbit averaged (constant) heat load was defined for each component. The constant dissipations were used in conjunction with the orbit averaged external heat load to determine a realistic temperature. Internal power dissipation was modeled using heat load boundary conditions. 


\subsection{Modeling Parameters}

The I-DEAS TMG software uses a finite difference method to solve the heat balance equation and to get the temperature distribution in the model. The heat balance equation for a transient run to be solved iteratively at iteration $n+1$ and time $t+\Delta t$ for element $i$ can be cast in the form [6]:

$$
\begin{aligned}
\frac{C_{i, t}\left(T_{i, t+\Delta t, n+1}-T_{i, t}\right)}{\Delta t}= & Q_{i, t+\Delta t}(t)+\alpha_{s} A_{s} q_{i, t+\Delta t}^{S}(t)+\alpha_{s} A_{A} q_{i, t+\Delta t}^{A}(t)+\varepsilon A_{E} q_{i, t+\Delta t}^{E}(t)- \\
& \sigma \sum_{j=1}^{N} F_{i j} A_{i j}\left(T_{j, t+\Delta t, n+1}^{4}-T_{i, t+\Delta t, n+1}^{4}\right)-\left(\sum_{j=1}^{N} K_{i j}\left(T_{j, t+\Delta t, n+1}-T_{i, t+\Delta t, n+1}\right)\right.
\end{aligned}
$$

where

$\mathrm{C}_{\mathrm{i}, \mathrm{t}}=$ the capacitance of the element

$T_{i, t+d t, n+1}=$ the temperature of element $\mathrm{i}$ at time $\mathrm{t}+\mathrm{dt}$ and iteration $\mathrm{n}+1$

$\mathrm{n}=$ the current iteration value

$\mathrm{T}_{\mathrm{i}, \mathrm{t}}=$ the temperature of element $\mathrm{i}$ at time $\mathrm{t}$

$\Delta t=$ the integration time step

$Q_{i, t+d t}(t)=$ the heat generation rate of element $i$ as a function of time at time $t+d t$

$\mathrm{G}_{\mathrm{ij}}=$ the sum of the conductive conductances between $\mathrm{i}$ and $\mathrm{j}$

$\sigma=$ Stefan Boltzmann constant

$F_{i j}=$ gray body view factor between elements $i$ and $j$

$A=$ radiating surface area of element $i$

The Backward method was used to solve equation (2). In particular, it is most effective for this model where $\tau_{\min }$ is small compared to the solution interval. In addition, it is more accurate than the Forward-Backward method under conditions of rapid temperature change.

Listing of Transient Analysis Parameters

- Start Time $=0.0$ seconds

- $\quad$ End Time = 116686.8 seconds

- Integration Method: Backward

- $\quad$ Time Step value $=58.8$ seconds

- Maximum Number of Iterations $=500$

- Relaxation Factor $=0.05$

- Temperature Difference for Convergence $=0.1$

Listing of Solution Methods

- Solution Method: Conjugate Gradient 
- Iteration Limit $=300$

- Convergence Criterion = 0.1

- Preconditioning Matrix Fill value $=10$

\section{THERMAL ANALYSIS RESULTS}

In this section, the thermal analysis of the satellite will be discussed. Table 6 and Fig. 7 present temperature distribution on the satellite case components. The thermal analysis was performed to evaluate the thermal transient over an orbit and to define the thermal gradient across the different components.

By referring to the thermal results gained above, the structure will not experience high temperatures during the mission. Inspection of the above results appears that the maximum temperatures occur at the onboard computer frame modules $(25.2$ ${ }^{\circ} \mathrm{C}$ ). As one can notice from Table 6 , there is a difference of $6^{\circ} \mathrm{C}$ between two sides of the first onboard computer frame module. This temperature difference is due to the temperatures of the heat shields. The heat shields have a direct impact on the temperature of the frame modules as from facing the heat shield facing the sun or deep space. As it has been showed in Fig. 7, the temperature gradient between the plates did not exceed $5^{\circ} \mathrm{C}$.

Temperature drop in height of reinforcing ribs was taken equal to $0.2{ }^{\circ} \mathrm{C}$. For plates this temperature increases in the direction of an mounting plate, and for a case of a basis unit - inwards of a basic unit. In calculation of thermal strains of the plates and basic unit case, a temperature drop in height of reinforcing ribs was taken into account. In calculation of cases of frame modules this drop was not taken into account, since it effects slightly on angular deviations of instruments requiring an accurate installation. These temperature distributions are applied in a finite-element model as boundary conditions and thermal analysis is executed but using FE technique this time. This step is done to account for the mesh difference between finite-difference model and the finite-element one.

\section{FINITE-ELEMENT, THERMAL AND STRUCTURE ANALYSES}

Temperature changes can affect structures in many ways. Most materials expand when heated and contract when cooled. In space, the sun ensures that an orbiting satellite's temperatures are neither uniform nor constant. As a result, satellite structure distorts. The materials that make up a satellite structure expand or contract different amounts as temperatures change. Thus, resulting in stresses that can cause them to yield, rupture, or fatigue. High temperatures usually degrade material strength and stiffness. Structure designers should understand thermal environments and requirements. 
Thermal deformations (rotational angle around $\mathrm{X}, \mathrm{Y}$, and $\mathrm{Z}$ w.r.t Basic coordinate system of Satellite, Fig. 8) are evaluated for the worst case (maximum temperature). The origin of the base coordinate system (BCS) $\mathrm{O}_{5}$ in the plane of the star sensor mounting seat on bracket and coincides with the center of the segment of a tangent line to two high-accuracy studs on the side, that is closer to the basis unit center. $X_{\bar{b}}$ axis coincides with the above-mentioned tangent and is directed towards stabilization plane $I . Z_{E}$ axis is directed towards the satellite base, perpendicular to $X_{5}$ axis and is located at an angle of $41^{\circ}$ relative to the star sensor-bracket interface plane. $Y_{5}$ axis provides a right-handed coordinate system. This worst case was determined by performing thermal analysis of satellite structure in orbit by the thermal analysis engineer (Table 6 \& Fig.9).

Material of all structural elements in the ÀMã6-ì alloy with Thermal Conductivity $\mathrm{K}_{\mathrm{xx}}=$ $117 \mathrm{~W} / \mathrm{m}^{\circ} \mathrm{c}^{\circ}$, Coefficient of thermal expansion $=24.7 \mathrm{E}-6 \mathrm{deg}^{-1}$, and $\mathrm{T}_{\mathrm{Ref}}=$ Temperature at Star Sensor Seats.

Analysis of thermal strains of a satellite structure was performed by the finite element method (FEM) using the ANSYS program. FEM is one of the main computational techniques of problems of the continuous medium mechanics. The idea of this technique is in an approximation of the continuous medium with an infinitely large number of degrees of freedom by a combination of simple elements having a finite number of degrees of freedom and related among themselves at nodal points.

Superelement method is applied. All the super-elements among themselves and virtual part were related by contours of holes; these holes were intended for studs connecting the satellite structure as a monoblock (unit). Walls of the basis unit case were connected by contours of holes; these holes were intended for screws securing the walls among themselves.

Super-element part of the model was decomposed into four elements (Fig.9):

- base;

- frame of a basis unit case;

- case of a basis unit with a truss of the angular velocity meter;

- mounting plate.

Model was decomposed into structural volume finite elements solid 92.

Instruments requiring an accurate installation were as plates in the design diagram; these plates were hinged to the attachment points of respective instruments.

Modulus of elasticity of these plates (to avoid an effect of their stiffness on thermal strains was taken equal to a modulus of metal elasticity of the main structure; modulus of elasticity of plates was less than a modulus of metal elasticity by two orders of magnitude. Apply displacement boundary conditions by fixing one of the star sensor four points of fixation (on bracket) in ' $z$ ' directions. Then, fix the next point in the ' $x, z$ '. Fix the other two points in the ' $y, z$ ' direction only. 
All virtual structures of the ADCS and payload devices are replaced by thin plate of thickness = ' $1 \mathrm{~mm}$ ' and modulus of elasticity = ' $E / 100$ ' to avoid influence of plate on thermal deformation. Rotational deformation of each device w.r.t basic axes is determined at the center of each plate.

Performing thermal deformation analysis is determined using ANSYS for the Basis Unit Block where all ADCS equipments and the two imagers are installed. Review results and record those in table for later use of mounting accuracy after the effect of static and dynamic loads have been determined. UNITS of rotation deformation calculated from ANSYS are RAD, so we need to multiply by ' $(180 / \pi){ }^{*} 60$ ' to represent results in 'ARCMIN' format.

Thermal deformation (rotations) relative to basic coordinate system is listed in Table 7. Figures 10 to 12 show thermal rotation of the two imagers and reaction wheel- 4 .

\section{CONCLUSION}

The finite-difference method is excellent for building satellite model. The method is compatible with the basic surface primitives, e.g., cones, cylinders, spheres, etc., used to describe spacecraft surfaces in the radiation codes. The finite element mesh does not have to be uniform. The accuracy of the method is judges by the truncation error from Taylor expansion. The truncation error can be reduced with smaller mesh and smaller time steps. The finite-element method is extensively used in structural analysis. The method is excellent for solving thermal/stress problems. Normally the structural model requires more detail than the equivalent thermal model. The real strength of finite-element techniques are the mesh generation schemes. These techniques cab easily handle irregular surface shapes. This is why finite-element mesh-generating scheme have been used to develop and post-process finitedifference temperature results.

Thermal analysis was executed applying finite-difference method (IDEAS), and then the temperature profile that is evaluated is applied as boundary condition in the finite-element model (ANSYS). Perform thermal analysis using finite element model to interpolate temperature profile to the finite-element mesh. Thermal deformations are then calculated and recorded for the payload and ADCS equipments seats mounting accuracy evaluation process.

\section{REFERENCES}

[1] Gilmore, D., "Satellite Thermal Control Handbook", The Aerospace Corp. Press, El Segundo, CA, (1994).

[2] Karam, R. D., "Satellite Thermal Control for System Engineer", McGraw-Hill, New York, (1998) 
[3] Tsai, J. R., "Overview of Satellite Thermal Analytical Model", Journal of Spacecraft and Rockets, Vol. 41, pp. 120-125, (2004).

[4] Muroaka, I., Leite, R.M.G., and Bastos, J.L.F., "Thermal Design Concept of China Brazil Earth Resources Satellite", International Conference on Environment Systems, 21st, San Francisco, CA, 1991.

[5] Moffitt, B.A., "Predictive Thermal Analysis of the Combat Sentinel Satellite", Proceedings, 16th Annual AIAA/USU Conference on small satellites, Logan, Utah State University, 2002.

[6] I-DEAS TMG Reference Manual, MAYA Heat Transfer Technologies Ltd., January (2003).

[7] NARSS report, "Satellite Preliminary Design. Composition and Main Characteristics" (2003).

[8] NARSS report, "Satellite Structure. Verification plan" (2003).

[9] NARSS report, "Satellite. Determination and Adjustment of Position of Mounting Seats for Instruments Instruction" (2003).

[10] NARSS report, "Satellite. Report on Analysis of Temperature Deformation" (2003).

[11] Thomas P. Sarafin," Spacecraft Structures and Mechanisms. From Concept to Launch". Kluwer Academic Publishers (1998).

Design" (1998).

[12] Russell C. Hibbeler, "Structural Analysis, 3rd". PRENTICE HALL, Inc (1995).

[13] Nelson R. Bauld, "Mechanics of Materials". PWS Publishers (1986). 
Table 1. Satellite general information

\begin{tabular}{|l|l|}
\hline Orbit & $\begin{array}{l}\text { Sun-synchronous, polar } \\
\text { Altitude: } 668 \mathrm{~km} \\
\text { Inclination: } 98^{\circ} \\
\text { Local time of descending node: } 10 \mathrm{hr}: 30 \mathrm{~min}\end{array}$ \\
\hline Mass & $\cong 110 \mathrm{~kg}$ \\
\hline Power & $65 \mathrm{~W}$ \\
\hline Size & $640 \times 640 \times 680 \mathrm{~mm}$ \\
\hline Payload & Multi-band Earth Imager \\
\hline
\end{tabular}

Table 2. Geometrical dimensions and mass of the different components of the 1DEAS model

\begin{tabular}{|c|c|c|c|c|c|c|}
\hline COMPONENT & SHAPE & $\begin{array}{c}\text { DIMENSION } \\
1 \\
(\mathrm{MM})\end{array}$ & $\begin{array}{c}\text { DIMENSION } \\
2 \\
(M M) \\
\end{array}$ & $\begin{array}{c}\text { DIMENSION } \\
3 \\
(M M) \\
\end{array}$ & $\begin{array}{l}\text { THICKNESS } \\
\text { (MM) }\end{array}$ & $\begin{array}{c}\text { MASS } \\
\text { (KG) }\end{array}$ \\
\hline $\begin{array}{c}\text { Upper and } \\
\text { lower mounting } \\
\text { plate }\end{array}$ & Parallelepiped & Length: 640 & Height: 640 & 20 & 1.5 & 4.7 \\
\hline Solar array & Parallelepiped & Length: 576 & Height: 695 & & 15 & 0.8 \\
\hline $\begin{array}{l}\text { Multi-band } \\
\text { Earth imager }\end{array}$ & Cylinder & $\begin{array}{c}\text { Diameter: } \\
200\end{array}$ & Height: 480 & & & 30 \\
\hline $\begin{array}{c}\text { Store and } \\
\text { forward } \\
\text { communications } \\
\text { payload }\end{array}$ & Box & Length: 180 & Height: 180 & Depth: 100 & & 9.5 \\
\hline Antenna-1 & Disk & $\begin{array}{l}\text { Diameter: } \\
200\end{array}$ & 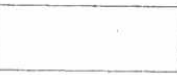 & & 5 & 1.8 \\
\hline Antenna-2 & Cone & $\begin{array}{l}\text { Diameter: } \\
100\end{array}$ & & & 1.5 & 0.5 \\
\hline Antenna-3 & Cylinder & Diameter: 60 & Height: 100 & & 1.5 & 0.15 \\
\hline Heat shield & Parallelepiped & Length: 626 & Height: 687 & & 0.2 & 0.23 \\
\hline Battery module & Box & Length: 380 & Height: 300 & Depth: 90 & 1.5 & 13.5 \\
\hline $\begin{array}{c}\text { Transmitter } \\
\text { module }\end{array}$ & Box & Length: 380 & Height: 300 & Depth: 150 & 1.5 & 8.5 \\
\hline $\begin{array}{l}\text { Power } \\
\text { regulating unit } \\
\text { module }\end{array}$ & Box & Length: 380 & Height: 300 & Depth: 105 & 1.5 & 5.4 \\
\hline $\begin{array}{l}\text { Attitude control } \\
\text { module }\end{array}$ & Box & Length: 380 & Height: 300 & Depth: 180 & 1.5 & 17.5 \\
\hline
\end{tabular}


Table 3. Physical properties of the different materials used in the I-DEAS model

\begin{tabular}{|c|c|c|c|c|}
\hline COMPONENT & MATERIAL & $\begin{array}{l}\text { DENSITY } \\
\left(\mathrm{KG} / \mathrm{M}^{3}\right)\end{array}$ & $\begin{array}{l}\text { THERMAL } \\
\text { CONDUCTIVITY } \\
\left(\mathrm{W}_{\mathrm{M}^{2}}{ }^{2} \mathrm{~K}\right)\end{array}$ & $\begin{array}{c}\text { HEAT } \\
\text { CAPACITY } \\
\text { (J/KG.K) }\end{array}$ \\
\hline $\begin{array}{l}\text { Upper and } \\
\text { lower mounting } \\
\text { plates }\end{array}$ & $\begin{array}{l}\text { Aluminum } \\
\text { 2024-Tx }\end{array}$ & 2769 & $\begin{array}{c}120(20 \pm 20) \\
125(150)\end{array}$ & 936 \\
\hline Solar array & $\begin{array}{l}\text { Aluminum } \\
2024-T x\end{array}$ & 2769 & $\begin{array}{c}120(20 \pm 20) \\
125(150)\end{array}$ & 936 \\
\hline $\begin{array}{l}\text { Multi-band } \\
\text { Earth imager }\end{array}$ & $\begin{array}{l}\text { Titanium } \\
\text { alloys }\end{array}$ & 4430 & 7 & 540 \\
\hline $\begin{array}{c}\text { Store and } \\
\text { forward } \\
\text { communications } \\
\text { payload }\end{array}$ & $\begin{array}{l}\text { Aluminum } \\
\text { 2024-Tx }\end{array}$ & 2769 & $\begin{array}{c}120(20 \pm 20) \\
125(150)\end{array}$ & 936 \\
\hline Antenna-1 & $\begin{array}{l}\text { Aluminum } \\
\text { 2024-Tx }\end{array}$ & 2769 & $\begin{array}{c}120(20 \pm 20) \\
125(150)\end{array}$ & 936 \\
\hline Antenna-2 & $\begin{array}{l}\text { Aluminum } \\
\text { 2024-Tx }\end{array}$ & 2769 & $\begin{array}{c}120(20 \pm 20) \\
125(150)\end{array}$ & 936 \\
\hline Antenna-3 & $\begin{array}{l}\text { Aluminum } \\
2024-T x\end{array}$ & 2769 & $\begin{array}{c}120(20 \pm 20) \\
125(150)\end{array}$ & 936 \\
\hline Heat shield & $\begin{array}{l}\text { Aluminum } \\
\text { (honeycomb } \\
\text { core) } \\
\text { 2024-Tx }\end{array}$ & 2769 & $\begin{array}{c}120(20 \pm 20) \\
125(150) \\
k_{x}=0.4 \\
k_{y}=0.6 \\
k_{z}=1.067\end{array}$ & 936 \\
\hline
\end{tabular}


Table 4. Thermo-optical properties of the different coatings applied on the different components

\begin{tabular}{|c|c|c|c|}
\hline COMPONENT & COATING & $\varepsilon$ & $\alpha_{\mathrm{S}}$ \\
\hline $\begin{array}{c}\text { Upper andjlower } \\
\text { mounting plates }\end{array}$ & $\begin{array}{c}\text { Chemglaze Black } \\
\text { paint Z306 } \\
\text { Solar array }\end{array}$ & 0.91 & 0.96 \\
\cline { 2 - 4 } & $\begin{array}{c}\text { Solar cell } \\
\text { Rear substrate }\end{array}$ & 0.83 & 0.76 \\
\hline $\begin{array}{c}\text { Multi-band Earth } \\
\text { imager }\end{array}$ & $\begin{array}{c}\text { Chemglaze Black } \\
\text { paint Z306 }\end{array}$ & 0.91 & 0.54 \\
\hline $\begin{array}{c}\text { Store and forward } \\
\text { communications } \\
\text { payload }\end{array}$ & $\begin{array}{c}\text { Chemglaze white } \\
\text { paint A276 }\end{array}$ & 0.88 & 0.96 \\
\hline Antenna-1 & Uncoated & 0.5 & 0.23 \\
\hline Antenna-2 & Uncoated & 0.5 & 0.7 \\
\hline Antenna-3 & Uncoated & 0.5 & 0.7 \\
\hline Heat shield & $\begin{array}{c}\text { Chemglaze Black } \\
\text { paint Z306 }\end{array}$ & 0.91 & 0.96 \\
\hline MLI & Aluminized & 0.48 & 0.81 \\
\hline $\begin{array}{c}\text { Battery, } \\
\text { communication, } \\
\text { power regulating } \\
\text { unit, attitude } \\
\begin{array}{c}\text { control, and } \\
\text { onboard modules }\end{array}\end{array}$ & $\begin{array}{c}\text { Chemglaze white } \\
\text { paint A276 }\end{array}$ & 0.88 & 0.23 \\
\hline
\end{tabular}

Table 5. Thermal design orbit parameters

\begin{tabular}{|c|c|}
\hline PARAMETER & ORBIT 1 \\
\hline Altitude $(\mathrm{km})$ & 668 \\
\hline Inclination & $98^{\circ}$ \\
\hline Period (min) & 97.239 \\
\hline Earth eclipse (min) & 34.995 \\
\hline Solar declination & $-23.45^{\circ}$ \\
\hline Solar radiation $\left(\mathrm{W} / \mathrm{m}^{2}\right)[3]$ & 1400 \\
\hline Albedo factor [3] & 0.42 \\
\hline Earth radiation $\left(\mathrm{W} / \mathrm{m}^{2}\right)[3]$ & 233.6 \\
\hline$\beta$ angle & $23.7^{\circ}$ \\
\hline
\end{tabular}


Table 6. Temperature distribution on the satellite case components.

\begin{tabular}{|l|c|c|c|c|}
\hline \multicolumn{1}{|c|}{$\begin{array}{c}\text { Satellite Structure } \\
\text { Component }\end{array}$} & I & II & III & IV \\
\cline { 2 - 5 } & 24.2 & 21 & 18.2 & 23 \\
\hline $\begin{array}{l}\text { On-board computer } \\
\text { frame module-1 }\end{array}$ & 25.2 & 21.8 & 22.8 & 23.7 \\
\hline $\begin{array}{l}\text { On-board computer } \\
\text { frame module-2 }\end{array}$ & 21.9 & 19.5 & 19 & 20.5 \\
\hline $\begin{array}{l}\text { On-board computer } \\
\text { frame module-3 }\end{array}$ & 19.5 & 17.2 & 16.2 & 18.2 \\
\hline PCDHS frame module & 18.9 & 17.1 & 16.2 & 17.9 \\
\hline Basis unit walls & 18.2 & 16.6 & 16 & 16.7 \\
\hline S-band frame modules & 20.2 & 18.4 & 17.8 & 18.5 \\
\hline $\begin{array}{l}\text { GPS receiver frame } \\
\text { module }\end{array}$ & 22 & 19.5 & 18.9 & 19.8 \\
\hline PCU frame module & 20.3 & 18.1 & 17.4 & 18.3 \\
\hline Cell leveling unit & 17.9 & 17 & 16.5 & 17.5 \\
\hline Battery frame module & & & & \\
\hline
\end{tabular}

TABLE 7. List of Rotation Deformations of ACS \& Payload Equipments w.r.t. Basic coord. system.

\begin{tabular}{|l|c|c|c|c|c|c|}
\hline \multicolumn{1}{|c|}{$\begin{array}{c}\text { Satellite } \\
\text { Equipments }\end{array}$} & $\mathbf{R}_{\mathbf{X}}$, rad & $\mathbf{R}_{\mathbf{Y}}$, rad & $\mathbf{R}_{\mathbf{Z}}$, rad & $\mathbf{R}_{\mathbf{X}}$, arcmin & $\mathbf{R}_{\mathbf{Y}}$, arcmin & $R_{\mathbf{Z}}$ arcmin \\
\hline $\begin{array}{l}\text { Reaction } \\
\text { wheel-3 }\end{array}$ & $1,30 \mathrm{E}-05$ & $6,33 \mathrm{E}-05$ & $-7,03 \mathrm{E}-06$ & $4,46 \mathrm{E}-02$ & $2,18 \mathrm{E}-01$ & $-2,42 \mathrm{E}-02$ \\
\hline $\begin{array}{l}\text { Reaction } \\
\text { wheel-1 }\end{array}$ & $7,20 \mathrm{E}-05$ & $5,86 \mathrm{E}-05$ & $2,70 \mathrm{E}-05$ & $2,47 \mathrm{E}-01$ & $2,02 \mathrm{E}-01$ & $9,30 \mathrm{E}-02$ \\
\hline Gyro-3 & $1,06 \mathrm{E}-04$ & $1,18 \mathrm{E}-04$ & $-9,95 \mathrm{E}-06$ & $3,65 \mathrm{E}-01$ & $4,04 \mathrm{E}-01$ & $-3,42 \mathrm{E}-02$ \\
\hline Gyro-1 & $5,31 \mathrm{E}-05$ & $8,47 \mathrm{E}-05$ & $-5,43 \mathrm{E}-05$ & $1,83 \mathrm{E}-01$ & $2,91 \mathrm{E}-01$ & $-1,87 \mathrm{E}-01$ \\
\hline Gyro-4 & $2,54 \mathrm{E}-05$ & $1,61 \mathrm{E}-01$ & $4,05 \mathrm{E}-06$ & $8,72 \mathrm{E}-02$ & $5,55 \mathrm{E}+02$ & $1,39 \mathrm{E}-02$ \\
\hline $\begin{array}{l}\text { Reaction } \\
\text { Wheel-4 }\end{array}$ & $4,46 \mathrm{E}-05$ & $7,37 \mathrm{E}-05$ & $1,40 \mathrm{E}-05$ & $1,53 \mathrm{E}-01$ & $2,54 \mathrm{E}-01$ & $4,82 \mathrm{E}-02$ \\
\hline MBEI & $1,02 \mathrm{E}-04$ & $1,10 \mathrm{E}-04$ & $-1,14 \mathrm{E}-05$ & $3,52 \mathrm{E}-01$ & $3,77 \mathrm{E}-01$ & $-3,91 \mathrm{E}-02$ \\
\hline MIREI & $8,46 \mathrm{E}-06$ & $1,82 \mathrm{E}-05$ & $-1,27 \mathrm{E}-05$ & $2,91 \mathrm{E}-02$ & $6,24 \mathrm{E}-02$ & $-4,38 \mathrm{E}-02$ \\
\hline
\end{tabular}




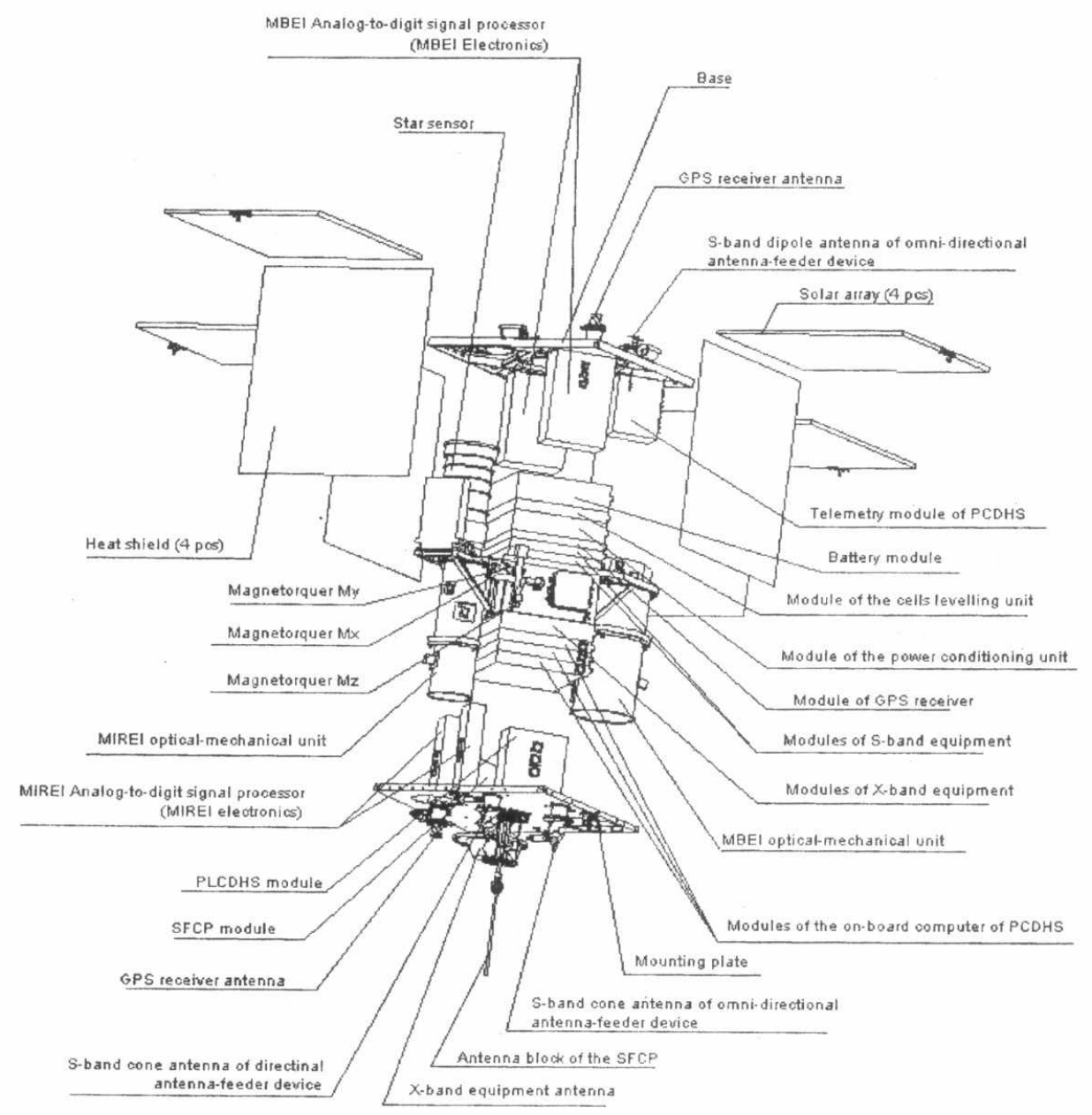

Fig.1. Exploded view of Micro-Satellite Subsystem. 


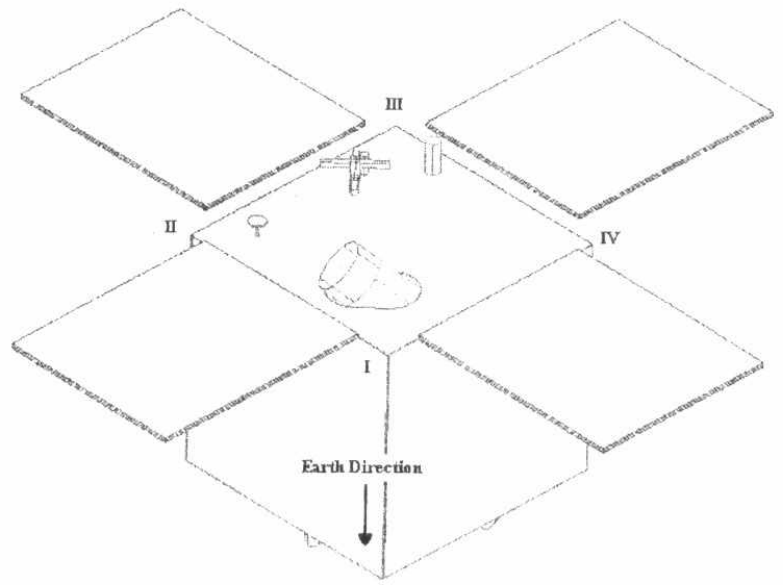

Fig. 2. Satellite main directions.

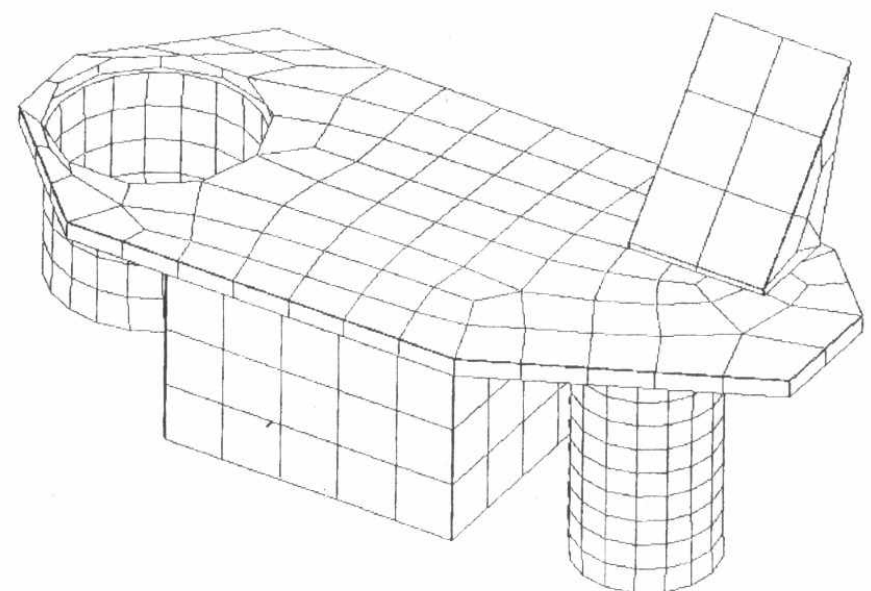

Fig. 3. Meshing of the basis unit block components 


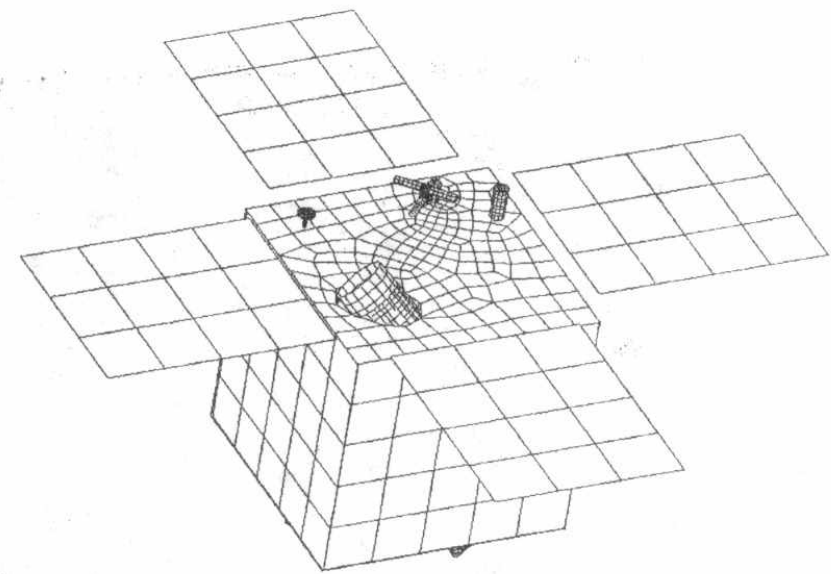

Fig. 4. The whole satellite after meshing.

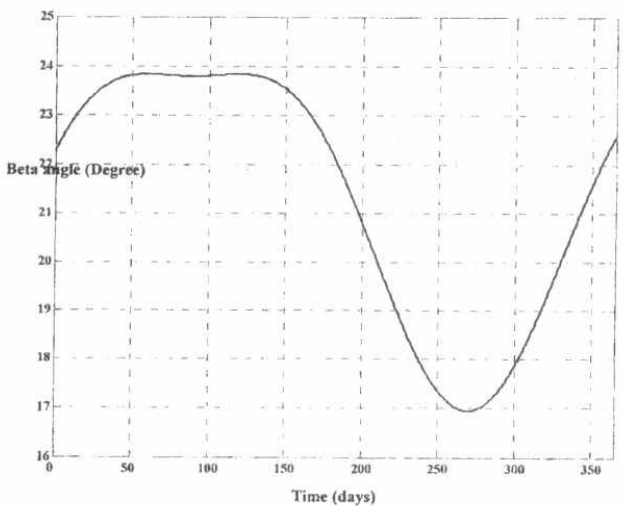

Fig. 5. $\beta$ angle history for sun synchronous orbit, $668 \mathrm{~km}$ altitude. 


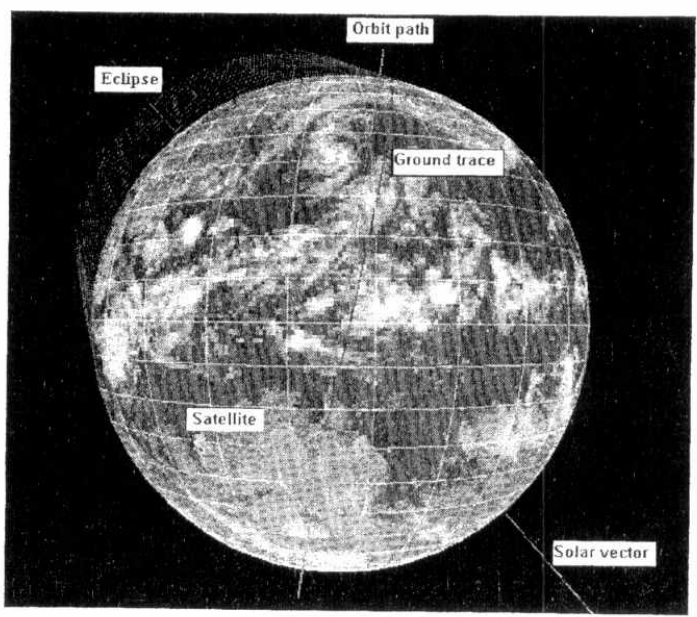

Fig. 6. The satellite as it appears during in-orbit.

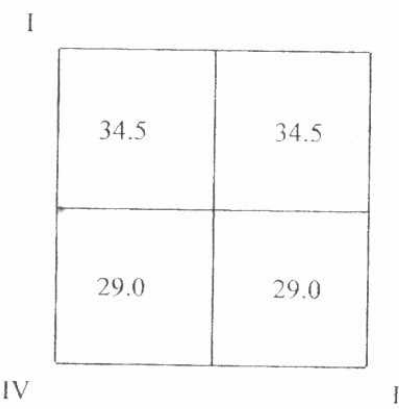

BASE

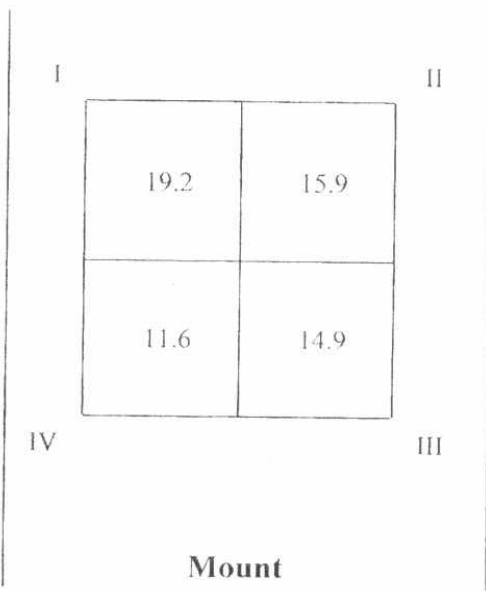

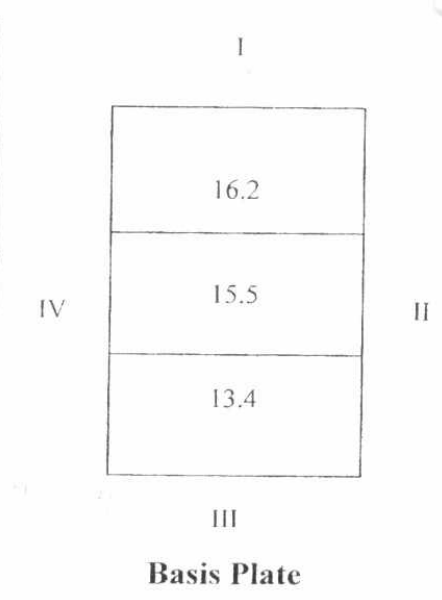

Fig 7. Temperature Distribution on Base, Mount, and Basis Unit Plates. 


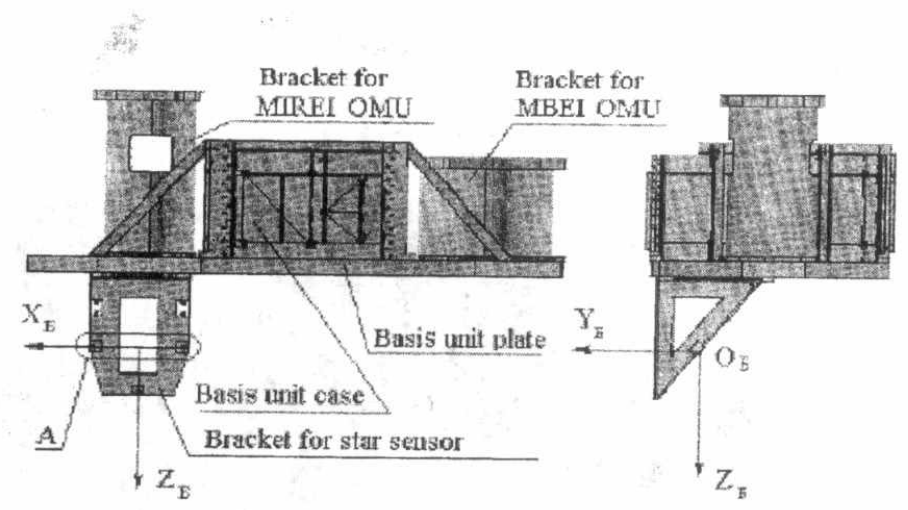

Fig.8. Basis Unit Structure.

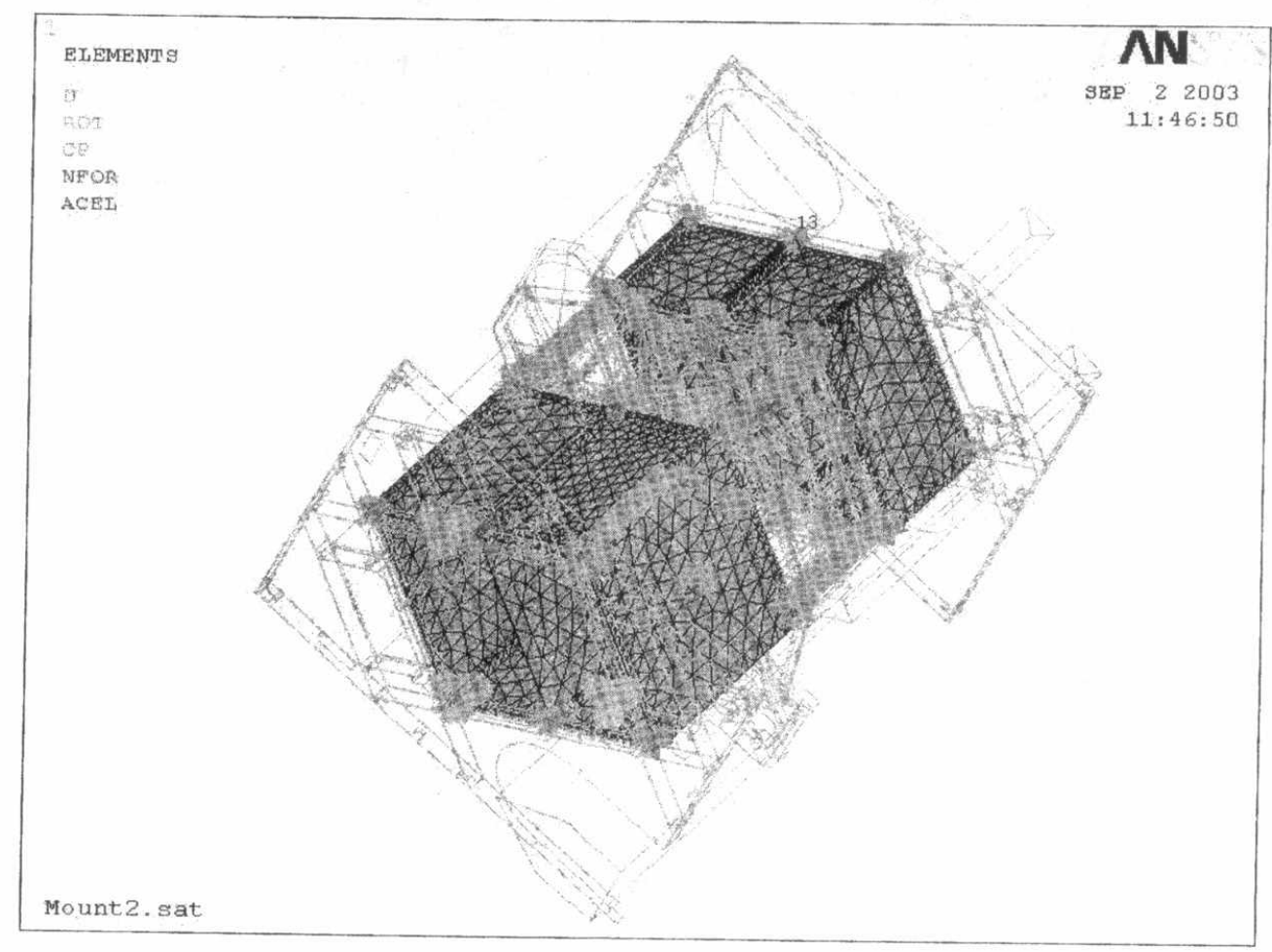

Fig 9. FE Model for Micro-Satellite. 


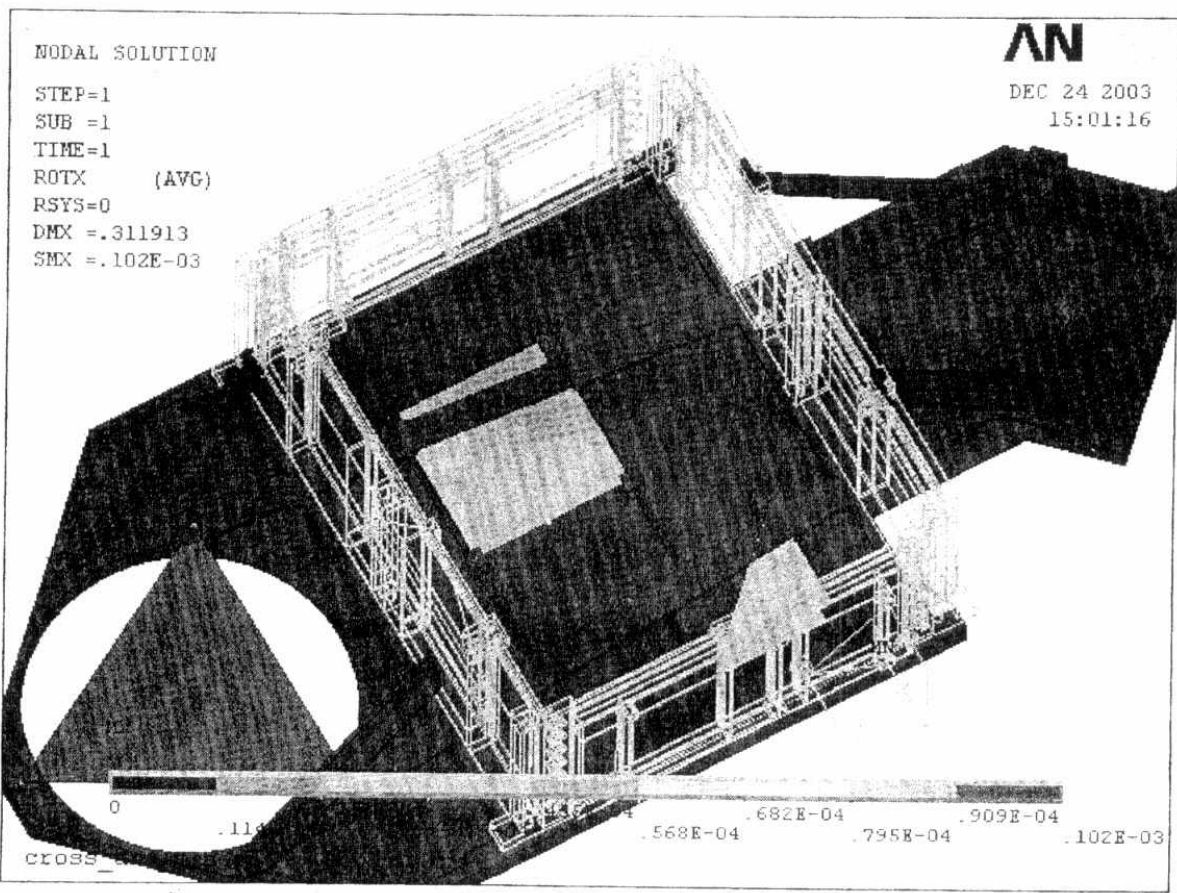

Fig. 10. Rotation@ @ axis of Basis Unit Plate 


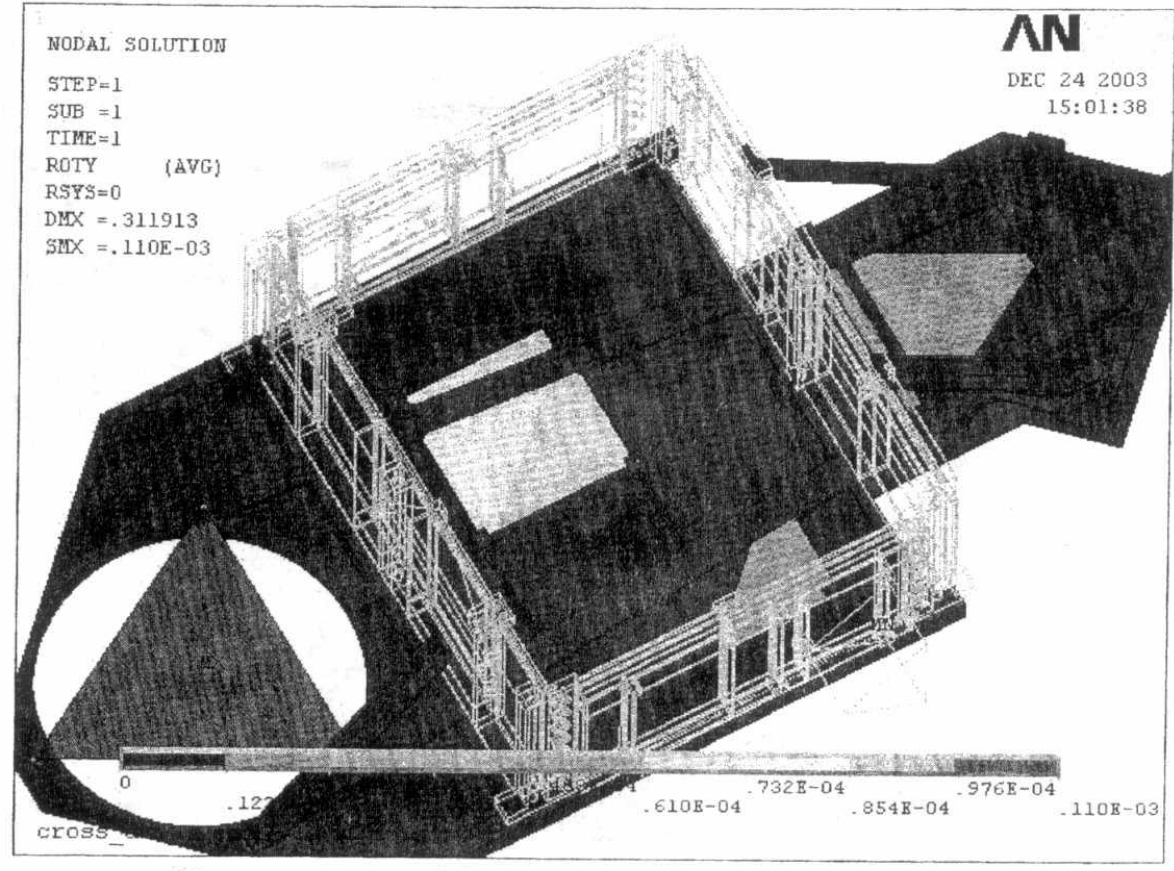

Fig. 11. Rotation @ Y axis of Basis Unit Plate. 


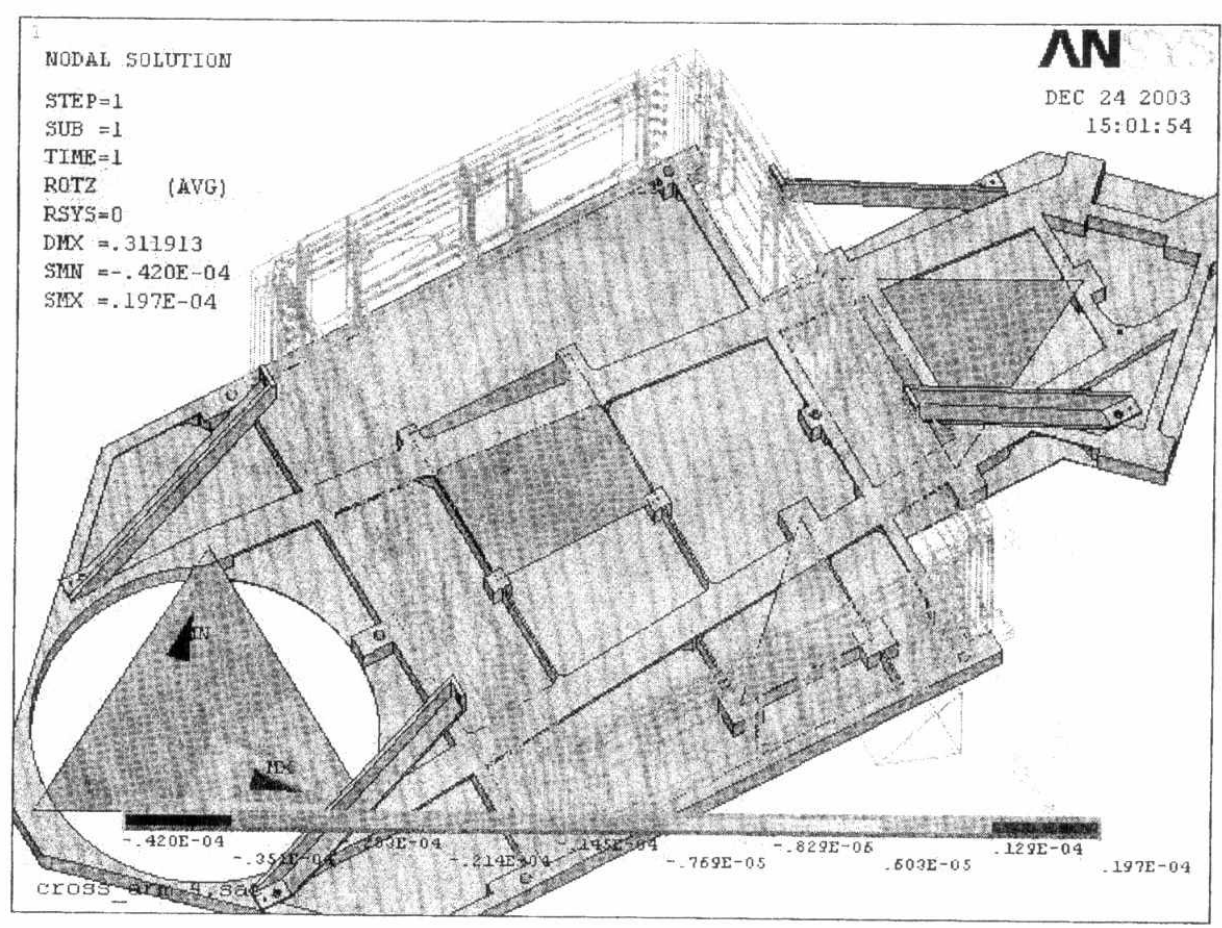

Fig. 12. Rotation@ $\mathrm{Z}$ axis of Basis Unit Plate. 